\title{
Görsel İletişim Tasarım Bölümü Öğrencilerinin Sektörel Logolardaki Renk Tercihleri
}

DOI: 10.26466/opus.905191

\section{Zafer Özomay $^{*}-$ Bekir Keskin $^{* *}$ - Cengiz Şahin ${ }^{* * *}$}

* Dr., Marmara Üniversitesi, Uygulamalı Bilimler Yüksekokulu, İstanbul, Türkiye

E-Posta: ozomay@marmara.edu.tr

ORCID: 0000-0002-7650-733X

** Dr., Ankara Hacı Bayram Veli Üniversitesi, Polatlı SBMYO, Ankara, Türkiye

E-Posta: bekir.keskin@hbv.edu.tr

ORCID: 0000-0001-9552-6272

* Dr., Ankara Yıldırım Beyazıt Üniversitesi, Güzel Sanatlar Fakültesi, Ankara, Türkiye

E-Posta: cengizsahin18@gmail.com

ORCID: $0000-0002-8348-0913$

\section{Öz}

Firmaların kurumsal kimlik ve logo tasarımında kullanılan renkler, hedef kitle ve müşteri algısının şekillenmesinde büyük bir etkiye sahiptir. Seçilen renkler, marka imajı ve firma hakkında ilk izlenimin oluşmasındaki etkisi bakımından oldukça önemlidir. İşletmeler kurumsal kimliklerini etkili hale getirmek ve hedef kitleye doğrudan ulaşmak üzere; kişilerin ilgisini çekecek, isteklerine hitap edecek renklere logo tasarımında yer vermelidir. İşletmelerin başarısının logo ve ambalaj seçimlerinde kullanılan renklerle ilişkili olduğu çeşitli araştırmalarla ortaya konmuştur. Bu çalışmada, farklı sektörlerde faaliyet gösteren 10 farklı sekör için tasarlanabilecek logolarda görsel tasarım eğitimi alan 319 öğrencinin tercih edecekleri renkler incelenmiştir. Öncelikle öğrencilerin bölümleri ile ilgili düşünceleri ve kendilerini tanımak için belirlenen sorular sorulmuştur. Araştırma kapsamına göre belirlenen să̆lık, gıda, otomotiv, yazllım, elektronik, eğitim gibi şirketlerde hangi renklerde logo belirledikleri cinsiyet, yaş, bir işte çalışıp çalışmamaları, mezun olduktan sonra çalışmak istedikleri alan gibi kriterler ile değerlendirilmiştir. Bu araştırma, görsel iletişim tasarımı bölümü öğrencilerinin gelişen tasarım ve renk belirleme konularına önemli teorik katkilar sağlamaktadır.

Anahtar Kelimeler: Görsel İletişim, Sektörel Logo, Renk, Tasarım 
ISSN: 2528-9527

E-ISSN : 2528-9535

Yıl Year: 11

Cilt Volume: 17

Sayı /ssue: 37

Mayıs May 2021

Makalenin Geliş Tarihi Received Date. 29/03/2021

Makalenin Kabul Tarihi Accepted Date. 26/05/2021

\title{
Color Preferences of Visual Communication Design Students in Sectoral Logos
}

\begin{abstract}
The colors used in the corporate identity and logo design of the companies have a great effect on shaping the target audience and customer perception. The colors chosen are very important in terms of the brand image and their effect on the first impression of the company. Businesses in order to make their corporate identities effective and reach the target audience directly; The colors that will attract people's attention and appeal to their requests should be included in the logo design. Various studies have revealed that the success of businesses is related to the colors used in logo and packaging choices.In this study, the colors preferred by 319 students studying visual design in logos that can be designed for 10 different sectors operating in different sectors were examined. First of all, the questions determined to get to know the thoughts of the students about their departments and themselves were asked. According to the scope of the research, the colors of the logo in companies such as health, food, automotive, software, electronics, education were evaluated with criteria such as gender, age, whether they work in a job, and the field they want to work after graduation. This research provides important theoretical contributions to the developing design and color determination issues of the students of the visual communication design department.
\end{abstract}

Anahtar Kelimeler: Visual Communication, Sectoral Logo, Color, Design 


\section{Giriş}

Renkler; hayatımızı şekillendirmekte, insanların çevre ve nesneler ile ilgili fikirlerinin oluşmasına katkı sağlamaktadır (Özalp ve Gökay, 2018, s.1310). Renklerin insanlar için anlamları dünyaya gelmeleri ile başlar ve yaşam boyunca devam eder. Renkler ve etkileri üzerine çok çeşitli araştırmalar yapılmaktadır (Boz vd., 2020, s. 9; Ceyhun Sezgin ve Ayyıldız, 2019, s.885). Bu araştırmaların sonuçları, insanların renkleri genel ve özel durumlarına bağlı olarak farklı algıladıklarını göstermektedir (Oduncu, 2019, s.511). Renklerin pozitif ve negatif anlamları renk seçimi aşamasına büyük önem kazanmaktadır (Ustaoglu ve Bayçu, 2019, s.34). Seçilen renk marka-ürün imajına büyük oranda etki etmektedir (Balcı vd., 2020, s. 4). Şöyle ki; tasarımda kullanılacak yeşil, kırmızı ya da mor rengin tüketici davranışları üzerinde olumlu ya da olumsuz etkileri oluşabilmektedir (Girard ve Hallman, 2017, s.74).

Renk, pazarlama stratejisi bakımından tüketicilere mesaj gönderen ve onların algılarının belirlenmesinde yön veren önemli bir iletişim aracıdır (Machado vd., 2021, s.159; El-Abbadi vd., 2020, s. 5). Pazarlama iletişiminde renklerin amacı insanların ilgisini çekmek ve olabildiğince uzun süre akılda kalmaktır (Mazlum, 2015, s.128). Ürünün hangi yaş grubuna, cinsiyete ya da sektöre yönelik olduğunu bilmek tasarımsal planlamada önemlidir (Özomay, 2020, s.142). Çeşitli araştırmalarda, ürün seçimi kararlarının verilmesinde yaklaşık \% 90 civarında bir oranla bilinçaltında bulunan renklerin önemli bir alanı oluşturduğu vurgulanmıştır (Mert, 2019, s.32). Ürün tercihlerinde, ürün hakkındaki fikir oluşmasının görme zamanından sonraki 90 saniye içinde gerçekleştiği öne sürülmektedir (Akkaya ve Kılınç, 2009, s. 2770). Bu gibi durumlardan dolayı tasarım aşamasında renklerin seçimi çok büyük önem kazanmaktadır.

Renkler psikolojik olarak bilinçaltımızı doğrudan etkileyerek insanlar üzerinde olumlu ya da olumsuz bir alg1 oluşturmaktadır (Tekvar, 2017, s.149). Belirli bir rengin her insan üzerinde farklı bir etkisi olabilmekle birlikte ve insanların algıladıkları renklere verdikleri anlamlarda farklılık göstermektedir (Sağocak, 2005, s.80) (Bilirdönmez, 2020, s.876). Bazı renkler ırksal, dini veya cinsel sinurlamalar olan evrensel bir mesaj iletebilmektedir.

Görsel tasarım eğitimi sürecinde, renk seçimleri öğretimi önemli bir yer oluşturmaktadır ( Şahin, Keskin ve Köse, 2016, s.53). Öğrenciler, tasarım 
dersinde boyutsal çerçeveyi ve yazı sistemlerinin kökenlerini gelişim süreci içerisinde bir bütün olarak tanımaktadırlar (Akkaya, 2008, s.58). Ayrıca çok boyutlu algılama, tasarlayıp uygulayabilme becerileri ile tasarım sürecinde kullanacakları renkleri belirleme becerileri zaman içerisinde gelişmektedir (Arabi, 2017, s.4).

Yapılan araştırmada, görsel iletişim tasarımı eğitiminde önemli bir yere sahip olan grafik tasarım konusunda öğrencilerin farkındalıkları çalışmanın önemini ortaya çıkarmaktadır. Tüm tasarım çalışmalarında farklı renk ve efektler kullanma eğiliminde olan öğrenciler, logo tasarımında rengin çok önemli bir unsur olduğunu yaptıkları proje ve çalışmalarla göstermektedirler.

Tipografik bir tercih olarak da düşünülebilecek olan logo tasarımlarında farklı figür ve şekillerden yararlanılmaktadır (Lipson vd., 2018, s. 5; Çalışkan ve Kılıç, 2014, s.75). Belediyeleri temsil eden logolarda da bölgenin coğrafi yapısı ve kültürel özelliklerinin yanı sıra kentsel kimlikleri de anlatan semboller ve renkler tespit edilmiştir (Bilirdönmez ve Şahin, 2019, s.46). Logoların görsel olarak vermek istedikleri mesajların etkili ve hedef kitleyi uyarabilecek düzeyde olması kullanılan figür-şekil ve renkler sayesinde sağlanabilmektedir (Uzuner, 2014, s.47).

Belirtilen durumlar dikkate alındığında; logo tasarımı ve renk seçimi konusunda, görsel tasarım eğitimi almakta olan öğrencilerden elde edilen verilerin istatistiksel olarak işlenmesi sayesinde ulaşılacak sonuçların renk seçimlerinde ve karar alma süreçlerinde rehberlik edici bilgiler sunacağı düşünülmektedir.

\section{Yöntem}

\section{Araştırmanın Yöntemi}

Görsel İletişim Tasarım Bölümü öğrencilerinin sektörel logolardaki renk tercihlerini betimlemeye yönelik bu araştırma, tarama araştırması (survey research) niteliğindedir. Tarama araştırmasının en önemli avantajı, rastgele seçilen geniş bir grubun belli konulardaki tutum ve davranışlarını öğrenmeye imkân sunmasıdır (VanderStoep \& Johnson, 2009).

Bu araştırmanın genel amacı Görsel İletişim Tasarım Bölümü öğrencilerinin sektörel logolardaki renk tercihlerini belirleyebilmektir. 
Yukarıda tespit edilen genel amaca ulaşabilmek için aşağıdaki sorulara cevap aranacaktır:

- Öğrencilerin logo tasarımı yaparken renk seçimlerini etkileyen unsurlar nelerdir?

- Öğrencilerin logo tasarımı yaparken en fazla tercih ettikleri renk hangisidir?

- Sağllk sektörü için logo tasarımı yaparken tercih ettikleri renk nedir?

- Otomotiv sektörü için logo tasarım yaparken tercih ettikleri renk nedir?

- Gıda sektörü için logo tasarımı yaparken tercih ettikleri renk nedir?

- Eğitim sektörü için logo tasarım yaparken tercih ettikleri renk nedir?

- Tekstil sektörü için logo tasarımı yaparken tercih ettikleri renk nedir?

- Yazılım ve Teknoloji sektörü için logo tasarımı yaparken tercih ettikleri renk nedir?

- Inşaat sektörü için logo tasarımı yaparken tercih ettikleri renk nedir?

- Turizm sektörü için logo tasarımı yaparken tercih ettikleri renk nedir?

- Bankacıllk sektörü için logo tasarımı yaparken tercih ettikleri renk nedir?

- Ulaştırma sektörü için logo tasarımı yaparken tercih ettikleri renk nedir?

- Öğrencilerin renk tercihlerine sebep olan unsurlar ile renk seçimleri arasinda anlamlı bir ilişki var mıdır?

- Öğrencilerin genel renk tercihleri ile sektörel renk seçimleri arasında anlamlı bir ilişki var mıdır?

\section{Evren ve Örneklem}

Araştırmanın evreni, Türkiye' de Görsel İletişim Tasarım Bölümü'nde okuyan tüm öğrencilerdir. Araştırmanın örneklemini ise bu evrenden rastgele seçilen kadın ( $n=198)$ ve erkek ( $n=121)$ toplam 319 öğrenci oluşturmaktadır.

\section{Araştırmanın Örnekleminin Özellikleri}

Araştırma örnekleminin; cinsiyet, yaş, kaçıncı sinıfta okuduğu ve bölümünü tercih sırası ile ilgili demografik özellikleri Tablo 1'de verilmiştir. 
Tablo 1. Ankete Katılan Öğrencilerin Cinsiyet, Yaş, Kaçıncı Sınıfta Okuduğu ve Bölümünü Tercih Sırası ile İlgili Demografik Özelliklerine Göre Dağılımı

\begin{tabular}{|c|c|c|c|c|}
\hline Demografik Özellikler & Seçenek & Siklık (f) & Yüzde (\%) & Toplam (\%) \\
\hline \multirow{2}{*}{ Cinsiyet } & Kadın & 198 & 62,1 & \multirow{2}{*}{100} \\
\hline & Erkek & 121 & 37,9 & \\
\hline \multirow{4}{*}{ Yaş } & $17-19$ & 102 & 32 & \multirow{4}{*}{100} \\
\hline & $20-22$ & 165 & 51,7 & \\
\hline & $23-25$ & 43 & 13,5 & \\
\hline & 26 üzeri & 9 & 2,8 & \\
\hline \multirow{4}{*}{ Sinif } & 1 & 135 & 42,3 & \multirow{4}{*}{100} \\
\hline & 2 & 137 & 42,9 & \\
\hline & 3 & 15 & 4,7 & \\
\hline & 4 & 32 & 10 & \\
\hline \multirow{5}{*}{ Tercih Sırası } & $1-3$ & 192 & 60,2 & \multirow{5}{*}{100} \\
\hline & $4-6$ & 70 & 21,9 & \\
\hline & $7-10$ & 27 & 8,5 & \\
\hline & $11-15$ & 20 & 6,3 & \\
\hline & 15 üzeri & 10 & 3,1 & \\
\hline
\end{tabular}

Tablo 1'e göre araştırmada anket uygulanan öğrencilerin \%62'si kadın, \%38'i erkektir. Ankete katılan öğrencilerin yarısı 20-22 yaş aralığındadır. Ankete katılan öğrencilerin \%42'si 1. sinıf, \%43'ü 2. sinıf, \%5'i 3. sinıf ve $\% 10$ ' u 4. sınıf öğrencisidir. Ankete katılan öğrencilerin \%80'inden fazlası ilk 6 tercihinde Görsel İletişim Tasarım Bölümü'nü tercih etmiş, dolayısıyla bu alanda eğitim almayı ve bölümlerini isteyerek seçen öğrencilerdir.

\section{Sayıltılar}

1) Araştırma kapsamındaki grupların anket sorularına verdikleri cevaplar doğrudur.

2) Literatürden elde edilen bilgiler doğrudur.

3) Çalışmaya dahil edilen örneklem grubu evreni temsil edecek niteliktedir.

\section{Sinirlilıklar}

Araştırma konu olarak Görsel İletişim Tasarım Bölümü öğrencilerinin sektörel logolardaki renk tercihleri ile sinırlı tutulmuştur. Bu araştırma Ekim 2020 ile Şubat 2021 tarihleri arasında gerçekleştirilmiştir. 


\section{Veri Toplama Tekniği}

$\mathrm{Bu}$ araştırmanın literatür bilgileri çeşitli kitap, dergi ve süreli yayınlardan ve internet üzerinden yapılan taramalardan faydalanılarak oluşturulmuştur. Bu araştırmada kullanılan veriler araştırmacılar tarafından geliştirilen ve iki bölümden oluşan veri toplama aracı ile toplanmıştır. Veri toplama aracının ilk bölümünü cinsiyet, yaş, kaçıncı sınıfta okuduğu ve okunan bölümün tercih sırası gibi demografik özellikler ile ilgili sorulardan oluşmaktadır. İkinci bölümde ise genel renk tercihleri, logolarda kullandığı renkleri tercih nedeni, farklı sektörlerin logoları için renk tercihleri ile ilgili sorular geliştirilmiş ve oluşturulan anket örneklem grubundaki öğrencilere online ortamda uygulanmıştır.

\section{Veri Analiz Tekniği}

Araştırma verileri bilgisayara girilirken öğrenci değişkenleri kodlanarak girilmiştir. Kodlama işleminden sonra verilerin analizi SPSS 24.0 paket programı kullanılarak yapılmış olup, çalışma grubunun tamamına temel tanımlayıcı istatistik yöntemleri uygulanmıştır. Yapılan analiz iki aşamadan oluşmaktadır. Birinci aşamada öğrencilerin tüm sorulara verdikleri yanıtlar yüzde-frekans tabloları ile gösterilmiştir. İkinci aşamada ise öğrencilerin renk tercihlerine sebep olan unsurlar ile renk seçimleri arasındaki ilişki ile genel renk tercihleri ile sektörel renk seçimleri arasındaki ilişki ki-kare testi ile açıklanmıştır. Verilerin analizinde önem düzeyi $p<0.05$ olarak kabul edilmiştir.

\section{Bulgu ve Yorumlar}

\section{Öğrencilerin Renk Tercihlerine Dair Bulgular}

Betimleyici analizde sıklık (frekans) ve yüzde (\%) kullanılmıştır.

Tablo 2. Görsel İletişim Tasarım Bölümü Öğrencilerinin Logo Tasarımı Yaparken Renk Seçimlerini Etkileyen Unsurların Dağılımı

\begin{tabular}{lll}
\hline Renk Seçimlerini Etkileyen Unsurlar & $\mathbf{N}(\mathbf{f})$ & $\mathbf{\%}(\mathbf{\%})$ \\
\hline Ürün renk uyumu & 107 & 33,5 \\
\hline Firmanın sektörü & 89 & 27,9 \\
\hline Müşteri isteği & 31 & 9,7 \\
\hline Hedef kitle & 87 & 27,3 \\
\hline Diğer & 5 & 1,6 \\
\hline Toplam & 319 & 100,0 \\
\hline
\end{tabular}


Tablo 2'ye göre Görsel İletişim Tasarım Bölümü öğrencilerinin logo tasarımı yaparken renk seçimlerini etkileyen unsurların dağılımı incelendiğinde öğrencilerin \%33'ünün renk seçimlerinde logosunu tasarladıkları ürünün renginden etkilendikleri; öğrencilerin \%28'inin logosunu tasarladıkları firmanın bağlı olduğu sektörden etkilendikleri; benzer bir oranla öğrencilerin \%27'sinin hedef kitleden etkilendiği; yaklaşı \%10'unun da müşterinin isteği doğrultusunda renk belirlediği tespit edilmiştir. Anket sorusunda yer alan diğer seçeneğini işaretleyen 5 öğrencinin etkilendiği diğer unsurlar ise: Temsil edilen objeyle renk uyumu sağlama, akılda kalıcılık, firmanın işlevselliği ve hedef kitle ile yönlendirmede 1srarcılık olduğunu belirtmişlerdir.

Tablo 3. Görsel İletişim Tasarım Bölümü Öğrencilerinin Logo Tasarımı Yaparken En Fazla Tercih Ettikleri Renklerin Dă̆ılımı

\begin{tabular}{lll}
\hline Renkler & Siklık (f) & Yüzde (\%) \\
\hline Kirmız1 & 82 & 25,7 \\
\hline Sarı & 12 & 3,8 \\
\hline Siyah & 95 & 29,8 \\
\hline Mavi & 58 & 18,2 \\
\hline Mor & 8 & 2,5 \\
\hline Turuncu & 20 & 6,3 \\
\hline Pembe & 5 & 1,6 \\
\hline Kahverengi & 3 &, 9 \\
\hline Yeşil & 10 & 3,1 \\
\hline Beyaz & 15 & 4,7 \\
\hline Diğer & 11 & 3,4 \\
\hline Toplam & 319 & 100,0 \\
\hline
\end{tabular}

Tablo 3'e göre Görsel İletişim Tasarım Bölümü öğrencilerinin logo tasarımı yaparken en fazla tercih ettikleri renklerin dağılımı incelendiğinde öğrencilerin \%30'unun siyah renk tercih ettiği, \%26 gibi yakın bir oranla kırmızı rengi tercih ettikleri ve öğrencilerin \%18'inin de mavi renk tercih ettiği tespit edilmiştir. En yüksek oranda tercih edilen bu 3 rengin dişında kalan renkler \%6 ve daha altında bir oranla tercih edilmişlerdir. Bu renkler tercih yüzdesine göre sırasıyla; turuncu, beyaz, sarı, yeşil, mor, pembe ve kahverengidir. Anket sorusunda yer alan diğer seçeneğini işaretleyen 11 öğrencinin 3'ü logo tasarımında en çok gri rengi tercih ettiğini, diğer öğrenciler ise; üreticinin isteklerine göre, soft, soft-nude, turkuaz, karışık renkli, en az iki 
renkli, kurumsal renk ve altın sarısı vb. renkleri tercih ettiklerini belirtmişlerdir.

Tablo 4. Görsel İletişim Tasarım Bölümü Öğrencilerinin Sağlık, Otomotiv, Gıda, Eğitim ve Tekstil Sektörleri İçin Logo Tasarımı Yaparken Tercih Ettikleri Renklerin Dă̆ılımı

\begin{tabular}{|c|c|c|c|c|c|c|c|c|c|c|}
\hline \multirow{2}{*}{$\begin{array}{l}\text { Sektörler } \\
\text { Renkler }\end{array}$} & \multicolumn{2}{|c|}{ Sağlık Sektörü } & \multicolumn{2}{|c|}{$\begin{array}{l}\text { Otomotiv Sek- } \\
\text { törü }\end{array}$} & \multicolumn{2}{|c|}{$\begin{array}{l}\text { Gida } \\
\text { Sektörüu }\end{array}$} & \multicolumn{2}{|c|}{ Eğitim Sektörü } & \multicolumn{2}{|c|}{ Tekstil Sektörü } \\
\hline & $\begin{array}{l}N \\
\text { (f) }\end{array}$ & $\begin{array}{l}\% \\
(\%)\end{array}$ & $\begin{array}{l}N \\
\text { (f) }\end{array}$ & $\begin{array}{l}\% \\
(\%)\end{array}$ & $\begin{array}{l}\mathrm{N} \\
\text { (f) }\end{array}$ & $\begin{array}{l}\% \\
(\%)\end{array}$ & $\begin{array}{l}N \\
\text { (f) }\end{array}$ & $\begin{array}{l}\% \\
\text { (\%) }\end{array}$ & $\begin{array}{l}\mathrm{N} \\
\text { (f) }\end{array}$ & $\begin{array}{l}\% \\
(\%)\end{array}$ \\
\hline Kırmızı & 69 & 21,6 & 58 & 18,2 & 108 & 33,9 & 44 & 13,8 & 31 & 9,7 \\
\hline Sar1 & 8 & 2,5 & 11 & 3,4 & 40 & 12,5 & 38 & 11,9 & 30 & 9,4 \\
\hline Siyah & 1 & 3 & 143 & 44,8 & 2 & 6 & 4 & 1,3 & 21 & 6,6 \\
\hline Mavi & 85 & 26,6 & 59 & 18,5 & 1 & 3 & 95 & 29,8 & 10 & 3,1 \\
\hline Mor & 1 &, 3 & 3 &, 9 & 3 &, 9 & 9 & 2,8 & 51 & 16,0 \\
\hline Turuncu & 4 & 1,3 & 16 & 5,0 & 50 & 15,7 & 48 & 15,0 & 43 & 13,5 \\
\hline Pembe & 11 & 3,4 & - & - & 6 & 1,9 & 11 & 3,4 & 49 & 15,4 \\
\hline Kahverengi & - & - & 8 & 2,5 & 9 & 2,8 & 5 & 1,6 & 47 & 14,7 \\
\hline Yeşil & 55 & 17,2 & 4 & 1,3 & 91 & 28,5 & 30 & 9,4 & 12 & 3,8 \\
\hline Beyaz & 85 & 26,6 & 17 & 5,3 & 9 & 2,8 & 35 & 11,0 & 25 & 7,8 \\
\hline Toplam & 319 & 100,0 & 319 & 100,0 & 319 & 100,0 & 319 & 100,0 & 319 & 100,0 \\
\hline
\end{tabular}

Tablo 4'te verilen Görsel İletişim Tasarım Bölümü öğrencilerinin sağlık, otomotiv, gıda, eğitim ve tekstil sektörleri için logo tasarımı yaparken tercih ettikleri renklerin dağılımı şu şekildedir:

Sağlık sektörü için logo tasarlarken öğrencilerin \%26'sının aynı oranla mavi ve beyaz renk tercih ettikleri, \%22'sinin kırmızl, \%17'sinin ise yeşil renk tercih ettiği tespit edilmiştir. Sağlık sektörü için tasarlanan logolarda en az tercih edilen renkler ise sirasılya; pembe, sarı, turuncu, siyah ve mordur. Kahverengi ise öğrenciler tarafından sağlık sektörü logoları için tercih edilmemiştir.

Otomotiv sektörü için logo tasarlarken öğrencilerin $\% 45^{\prime}$ inin siyah renk tercih ettikleri, \%18'inin aynı oranla kırmızı ve mavi renk tercih ettikleri tespit edilmiştir. Otomotiv sektörü için tasarlanan logolarda en az tercih edilen renkler ise sırasıyla; beyaz, turuncu, sarı, kahverengi, yeşil ve mordur. Pembe renginin ise öğrenciler tarafından otomotiv sektörü logoları için tercih edilmediği belirlenmiştir.

Gıda sektörü için logo tasarlarken öğrencilerin \%34'ünün kırmızı renk tercih ettikleri, \%28' inin yeşil, \%16'sının turuncu, \%12'sinin ise sarı renk ter- 
cih ettiği tespit edilmiştir. Gıda sektörü için tasarlanan logolarda en az tercih edilen renkler ise sirasıyla; kahverengi, beyaz, pembe, mor, siyah ve mavidir.

Eğitim sektörü için logo tasarlarken öğrencilerin \%30'unun mavi renk tercih ettikleri, \%15'inin turuncu, \%14'ünün kırmızl, \%12'sinin sarı, \%11'inin beyaz ve \%9'unun yeşil renk tercih ettiği tespit edilmiştir. Eğitim sektörü için tasarlanan logolarda en az tercih edilen renklerin ise sirasıyla; pembe, mor, kahverengi ve siyah olduğu tespit edilmiştir.

Tekstil sektörü için logo tasarlarken öğrencilerin diğer sektörlerde olduğunun aksine birkaç renk üzerine yoğunlaşmadıkları tespit edilmiştir. \%16 ile \%13 arasında değişen oranlarda en çok sırasılyla mor, pembe, kahverengi ve turuncu renkleri tercih ettikleri; \%10 ile \%7 arasında değişen oranlarda en çok sırasıyla kırmızı, sarı, beyaz ve siyah renkleri tercih ettikleri tespit edilmiştir. Tekstil sektörü için logo tasarlarken en az tercih edilen renklerin ise yeşil ve mavi olduğu belirlenmiştir.

Tablo 5. Görsel İletişim Tasarım Bölümü Öğrencilerinin Yazılım-Teknoloji, İnşaat, Turizm, Bankacılık ve Ulaştırma Sektörleri İçin Logo Tasarımı Yaparken Tercih Ettikleri Renklerin Dağılımı

\begin{tabular}{|c|c|c|c|c|c|c|c|c|c|c|}
\hline \multirow{2}{*}{$\begin{array}{l}\text { Sektörler } \\
\text { Renkler }\end{array}$} & \multicolumn{2}{|c|}{$\begin{array}{l}\text { Yazılım } \\
\text { Teknoloji }\end{array}$} & \multicolumn{2}{|c|}{$\begin{array}{l}\text { İnşaat } \\
\text { Sektörüu }\end{array}$} & \multicolumn{2}{|c|}{$\begin{array}{l}\text { Turizm } \\
\text { Sektörü }\end{array}$} & \multicolumn{2}{|c|}{$\begin{array}{l}\text { Bankacilık } \\
\text { Sektörü }\end{array}$} & \multicolumn{2}{|c|}{$\begin{array}{l}\text { Ulaştırma } \\
\text { Sektörü }\end{array}$} \\
\hline & $\begin{array}{l}\mathrm{N} \\
(\mathrm{f})\end{array}$ & $\begin{array}{l}\% \\
(\%)\end{array}$ & $\begin{array}{l}\mathrm{N} \\
\text { (f) }\end{array}$ & $\begin{array}{l}\% \\
(\%)\end{array}$ & $\begin{array}{l}N \\
\text { (f) }\end{array}$ & $\begin{array}{l}\% \\
(\%)\end{array}$ & $\begin{array}{l}\mathrm{N} \\
\text { (f) }\end{array}$ & $\begin{array}{l}\% \\
(\%)\end{array}$ & $\begin{array}{l}\mathrm{N} \\
\text { (f) }\end{array}$ & $\begin{array}{l}\% \\
(\%)\end{array}$ \\
\hline Kirm1z1 & 37 & 11,6 & 28 & 8,8 & 27 & 8,5 & 59 & 18,5 & 41 & 12,9 \\
\hline Sar1 & 24 & 7,5 & 45 & 14,1 & 45 & 14,1 & 15 & 4,7 & 44 & 13,8 \\
\hline Siyah & 65 & 20,4 & 62 & 19,4 & 6 & 1,9 & 10 & 3,1 & 26 & 8,2 \\
\hline Mavi & 85 & 26,6 & 20 & 6,3 & 85 & 26,6 & 91 & 28,5 & 92 & 28,8 \\
\hline Mor & 19 & 6,0 & 4 & 1,3 & 20 & 6,3 & 11 & 3,4 & 11 & 3,4 \\
\hline Turuncu & 31 & 9,7 & 43 & 13,5 & 45 & 14,1 & 30 & 9,4 & 30 & 9,4 \\
\hline Pembe & 2 & 6 & 3 & ,9 & 21 & 6,6 & 6 & 1,9 & 7 & 2,2 \\
\hline Kahverengi & 9 & 2,8 & 77 & 24,1 & 6 & 1,9 & 7 & 2,2 & 13 & 4,1 \\
\hline Yeşil & 15 & 4,7 & 13 & 4,1 & 50 & 15,7 & 62 & 19,4 & 25 & 7,8 \\
\hline Beyaz & 32 & 10,0 & 24 & 7,5 & 14 & 4,4 & 28 & 8,8 & 30 & 9,4 \\
\hline Toplam & 319 & 100,0 & 319 & 100,0 & 319 & 100,0 & 319 & 100,0 & 319 & 100,0 \\
\hline
\end{tabular}

Tablo 5'te verilen Görsel İletişim Tasarım Bölümü öğrencilerinin yazılım-teknoloji, inşaat, turizm, bankacılık ve ulaştırma sektörleri için logo tasarımı yaparken tercih ettikleri renklerin dağılımı şu şekildedir:

Yazılım-teknoloji sektörü için logo tasarlarken öğrencilerin \%27'sinin mavi renk tercih ettiği, \%20'sinin siyah, \%11'inin kırmızı ve \%10'unun ise 
aynı oranla beyaz ve turuncu renk tercih ettikleri tespit edilmiştir. Yazılımteknoloji sektörü için tasarlanan logolarda en az tercih edilen renkler ise s1rasıyla; sarı, mor, yeşil, kahverengi ve pembedir.

İnşaat sektörü için logo tasarlarken öğrencilerin \%24'ünün kahverengi renk tercih ettikleri, \%19'unun siyah, \%14'ünün aynı oranla sarı ve turuncu renkleri tercih ettikleri tespit edilmiştir. İnşaat sektörü için tasarlanan logolarda en az tercih edilen renklerin ise sırasıyla; kırmızı, beyaz, mavi, yeşil, mor ve pembe olduğu belirlenmiştir.

Turizm sektörü için logo tasarlarken öğrencilerin \%27'sinin mavi renk tercih ettikleri, \%16'sının yeşil, \%14'ünün aynı oranla sarı ve turuncu renk tercih ettiği tespit edilmiştir. Turizm sektörü için tasarlanan logolarda en az tercih edilen renkler ise sırasıyla; kırmızı, pembe, mor, beyaz, siyah ve kahverengidir.

Bankacilık sektörü için logo tasarlarken öğrencilerin \%29'unun mavi renk tercih ettikleri, \%19'unun aynı oranla yeşil ve kırmızı renk tercih ettiği tespit edilmiştir. Bankacılık sektörü için tasarlanan logolarda en az tercih edilen renklerin ise sirasıyla; turuncu, beyaz, sarı, mor, siyah, kahverengi ve pembe renkler olduğu belirlenmiştir.

Ulaştırma sektörü için logo tasarlarken öğrencilerin \%29'unun mavi renk tercih ettikleri, \%14'ünün sarl, \%13'ünün kırmızı ve \%9'unun aynı oranla turuncu ve beyaz renkler tercih ettikleri tespit edilmiştir. Ulaştırma sektörü için tasarlanan logolarda en az tercih edilen renkler ise sırasıyla; siyah, yeşil, kahverengi, mor ve pembedir.

\section{Değişkenlerin İlişki Durumlarna Dair Bulgular}

Görsel İletişim Tasarım Bölümü öğrencilerinin sektörel logolardaki renk tercihleri konusundaki anket sorularına verilen cevaplarda anlamlı bir ilişkinin olup olmadığının araştırılmasında "Ki-Kare" yöntemi kullanılmıştır. Ankete katılan öğrencilerin çeşitli değişken ve diğer sorularla yapılan KiKare testi değerlendirmesinde kurulan hipotezler aşağıdaki şekildedir:

H0: İlişki yoktur.

H1: İlişki vardır.

Verilerin analizinde önem düzeyi $p<0.05$ olarak kabul edilmiştir. Yani hesaplanan değer 0,05'ten büyükse H0 kabul edilmiş, dolayısıyla değişken- 
ler arasında anlamlı bir ilişki bulunmadığı; hesaplanan değer 0,05'ten küçükse H1 kabul edilmiştir. Bu durumda da değişkenler arasında anlamlı bir ilişki olduğu sonucuna ulaşılmıştır.

Çalışmanın bu aşamasında nitel bir değişken olan renk tercihlerine sebep olan unsurlar ile yine nitel birer değişken olan farklı sektörlere yönelik hazırlanacak olan logolarda tercih edilen renkler arasında bir ilişki olup olmadığı araştırılmıştır. İlgili analizlerde değişkenlerin nitel değişkenler olması nedeniyle uygulanan ki-kare bağımsızlık testi analiz sonuçları Tablo 6'da özetlenmiştir.

Tablo 6. Renk Tercihlerine Sebep Olan Unsurlar ile Genel ve Sektörel Bazda Renk Seçimleri Arasındaki İlişkiye Dair Bulgular

\begin{tabular}{lllll}
\hline & Sektör Renk Tercihi & $\mathbf{X}^{2}$ & $\mathbf{p}$ & \multicolumn{1}{c}{$\begin{array}{c}\text { Kabul } \\
\text { /Red }\end{array}$} \\
\hline & En fazla renk tercihi edilen renk seçimi & $2053.971^{\mathrm{a}}$ &, 000 & Kabul \\
\cline { 2 - 5 } & Sağlık sektörü renk seçimi & $213.337^{\mathrm{a}}$ &, 000 & Kabul \\
\cline { 2 - 5 } & Otomotiv sektörü renk seçimi & $181.214^{\mathrm{a}}$ &, 000 & Kabul \\
\cline { 2 - 5 } & Gida sektörü renk seçimi & $169.469^{\mathrm{a}}$ &, 000 & Kabul \\
\cline { 2 - 5 } $\begin{array}{l}\text { Renk tercihle- } \\
\text { rine sebep olä } \\
\text { unsurlar ile }\end{array}$ & Eğitim sektörün renk seçimi & $785.453^{\mathrm{a}}$ &, 000 & Kabul \\
\cline { 2 - 5 } & Tekstil sektörü renk seçimi & $367.795^{\mathrm{a}}$ &, 000 & Kabul \\
\cline { 2 - 5 } & Yazılım-teknoloji sektörü renk seçimi & $312.850^{\mathrm{a}}$ &, 000 & Kabul \\
\cline { 2 - 5 } & İnşaat sektörün renk seçimi & $282.725^{\mathrm{a}}$ &, 000 & Kabul \\
\cline { 2 - 5 } & Turizm sektörü renk seçimi & $305.099^{\mathrm{a}}$ &, 000 & Kabul \\
\cline { 2 - 5 } & Bankacıllk sektörü renk seçimi & $252.386^{\mathrm{a}}$ &, 000 & Kabul \\
\cline { 2 - 5 } & Ulaştırma sektörün renk seçimi & $278.217^{\mathrm{a}}$ &, 000 & Kabul \\
\hline
\end{tabular}

“Öğrencilerin renk tercihlerine sebep olan 'Ürün renk uyumu', 'Firmanın sektörü', 'Müşteri isteği' ve 'Hedef kitle' gibi unsurlar ile en fazla tercih edilen renk seçimleri arasında anlamlı bir ilişki vardır" hipotezine ilişkin uygulanan ki-kare analizinde $\mathrm{P}=0,000<0,05^{\prime}$ tir. Bu nedenle $\mathrm{H} 0$ hipotezi reddedilerek H1 hipotezi kabul edilir. Renk tercihlerine sebep olan unsurlar ile genel renk seçimleri arasında ilişki olduğu sonucuna varılır. P değeri 0,000 olduğu için ilişkinin güçlü olduğu söylenebilir.

“Öğrencilerin renk tercihlerine sebep olan 'Ürün renk uyumu', 'Firmanın sektörü', 'Müşteri isteği' ve 'Hedef kitle' gibi unsurlar ile sağlık, otomotiv, gıda, eğitim, tekstil, yazılım-teknoloji, inşaat, turizm, bankacılık ve ulaştırma sektörleri için logo tasarımında tercih edilen renkler arasında anlamlı bir ilişki vardır" hipotezine ilişkin uygulanan ki-kare analizinde $\mathrm{P}=0,000$ $<0,05$ 'tir. Bu nedenle H0 hipotezi reddedilerek H1 hipotezi kabul edilir. 
Renk tercihlerine sebep olan unsurlar ile sektörel bazda tercih edilen renk seçimleri arasında ilişki olduğu sonucuna varılır. P değeri 0,000 olduğu için ilişkinin güçlü olduğu söylenebilir.

Tablo 7. Logolarda Genel Renk Tercihleri ile Farklı Sektörlere Yönelik Renk Tercihleri Arasındaki İlişkiye Dair Bulgular

\begin{tabular}{lllll}
\hline & Sektör Renk Tercihi & $\mathbf{X}^{2}$ & $\mathbf{p}$ & $\begin{array}{l}\text { Kabul } \\
\text { /Red }\end{array}$ \\
\hline \multirow{4}{*}{$\begin{array}{l}\text { Genel } \\
\text { renk ter- } \\
\text { cihleri ile }\end{array}$} & Sağllk sektörü renk seçimi & $1696.293^{\mathrm{a}}$ &, 000 & Kabul \\
\cline { 2 - 5 } & Otomotiv sektörü renk seçimi & $1402.268^{\mathrm{a}}$ &, 000 & Kabul \\
\cline { 2 - 5 } & Glda sektörü renk seçimi & $1209.922^{\mathrm{a}}$ &, 000 & Kabul \\
\cline { 2 - 5 } & Eğitim sektörün renk seçimi & $1249.49^{\mathrm{a}}$ &, 000 & Kabul \\
\cline { 2 - 5 } & Tekstil sektörü renk seçimi & $1683.113^{\mathrm{a}}$ &, 000 & Kabul \\
\cline { 2 - 5 } & İnşaatlıt sektörün renk seçimi & $1496.298^{\mathrm{a}}$ &, 000 & Kabul \\
\cline { 2 - 5 } & Turizm sektörü renk seçimi & $1512.870^{\mathrm{a}}$ &, 000 & Kabul \\
\cline { 2 - 5 } & Bankacllı sektörü renk seçimi & $1362.430^{\mathrm{a}}$ &, 000 & Kabul \\
\cline { 2 - 5 } & Ulaştırma sektörün renk seçimi & $1527.735^{\mathrm{a}}$ &, 000 & Kabul \\
\hline
\end{tabular}

“Öğrencilerin logo tasarımı yaparken en fazla tercih ettikleri renkler ile sağlık, otomotiv, gıda, eğitim, tekstil, yazılım-teknoloji, inşaat, turizm, bankacılık ve ulaştırma sektörleri için logo tasarımında en fazla tercih ettikleri renkler arasında anlamlı bir ilişki vardır" hipotezine ilişkin uygulanan kikare analizinde $\mathrm{P}=0,000<0,05$ 'tir. Bu nedenle $\mathrm{H} 0$ hipotezi reddedilerek H1 hipotezi kabul edilir. En fazla tercih ettikleri renkler ile sektörel bazda tercih edilen renk seçimleri arasında ilişki olduğu sonucuna varılır. P değeri 0,000 olduğu için ilişkinin güçlü olduğu söylenebilir.

\section{Tartışma ve Sonuç}

Çalışma yakın gelecekte iki/üç boyutlu tasarım, animasyon, modelleme, karakter tasarımı, baskı vb. sektörlerde çalışacak potansiyel tasarımcıların tasarımın en önemli unsurlarından biri olan renk tercihleri noktasında önemli sonuçları ortaya koymaktadır. Katılımcı sayısının Türkiye genelindeki Görsel İletişim Tasarımı bölümü öğrencilerini önemli ölçüde temsil etmesi de gelecekte sektör çalışanlarının eğilimlerini tespit etmek ve eğitimleri devam ederken doğru yönlendirmelerin yapılabilmesi açısından akademiye de yol gösterici niteliktedir. 
Çalışmanın en önemli sonuçlarından biri Tablo 1'de elde verilerden elde edilen bulgulardır. Tabloya göre çalışmanın amacından bağımsız şekilde önemli bir sosyal sonucun ortaya çıkabileceği öngörülmektedir. Çalışma hayatında kadınların erkekler kadar yer bulamamasına karşılık Tablo 1' e göre Görsel İletişim Tasarımı alanında okuyan öğrencilerin cinsiyet açısından değerlendirildiğinde öğrencilerin \%62' sinin kadın olduğu tespit edilmiştir. Bu sonuçla gelecekte sektör çalışanları içinde kadınlar lehine bir gelişme olacağ1 söylenebilir.

Sektör isminden bağımsız olarak sonuçlar irdelendiğinde katılımcıların renk tercihinde ürün renk uyumu, firmanın yer aldığı sektör ve hedef kitle seçeneklerinin ön plana çıktığı görülmektedir.

Sektörden bağımsız olarak öğrencilerin logo tasarımlarında heyecan ve enerjinin temsilcisi Kırmızı, sadakat, sebat, güç, bilgelik ve güvenilirlik temsilcisi Siyah ve kararlılık, bağlılık ve dinlendiriciliğin sembolü Mavi renkler en çok tercih edilen renklerdir.

İstatistiksel analiz sonucunda katılımcıların renk uyumu, firmanın sektörü, müşteri isteği, hedef kitle özellikleri gibi unsurlarla logo renk tercihleri arasında güçlü bir ilişki olduğu belirlenmiştir. Ayrıca katılımcıların genel renk tercihleri ile logo tasarımında kullandıkları renkler arasında güçlü bir ilişki olduğu görülmüştür.

Sonuç olarak; tasarımda renk tercihleri tasarımcının genel eğilimleri ve firmaların sektörleri, hedef kitle, müşteri isteği gibi faktörlerden etkilenmektedir. Renk tercihlerinin şekillenmesinde tasarımcıların tecrübe ve deneyimleri ile sıralanan bu faktörlerin etkili olduğu belirlenmiştir. 


\title{
EXTENDED ABSTRACT
}

\section{Color Preferences of Visual Communication Design Students in Sectoral Logos}

\author{
Zafer Özomay - Bekir Keskin - Cengiz Şahin \\ Marmara Universtiy, Ankara Hacı Bayram-ı Veli University, Yıldırım Beyazıd University
}

The colors used in the corporate identity and logo design of the companies have a great effect on shaping the target audience and customer perception. The colors chosen are very important in terms of the brand image and their effect on the first impression of the company. Businesses in order to make their corporate identities effective and reach the target audience directly; The colors that will attract people's attention and appeal to their requests should be included in the logo design. Various studies have revealed that the success of businesses is related to the colors used in logo and packaging choices. In this study, the colors preferred by 319 students studying visual design in logos that can be designed for 10 different sectors operating in different sectors were examined. First of all, the questions determined to get to know the thoughts of the students about their departments and themselves were asked. According to the scope of the research, the colors of the logo in companies such as health, food, automotive, software, electronics, education were evaluated with criteria such as gender, age, whether they work in a job, and the field they want to work after graduation. This research provides important theoretical contributions to the developing design and color determination issues of the students of the visual communication design department.

The work will be in two / three dimensions design, animation, modeling, character design, printing etc. in the near future. It reveals important results in terms of color preferences, which is one of the most important design of the potential designers who will work in the sectors. It is also a guide for the academy to convey the important thoughts of its number to the employees of the Visual Communication Design department throughout Turkey, and not to provide guidance while their training continues. 
One of the most important results of the study is the findings obtained in Table 1. According to the table, it is predicted that a result may arise regardless of its social purpose. Despite not being able to find a place in working life as much as men, if the gender studying in the field of Visual Communication Design is criticized according to Table 1 , it has been determined that $62 \%$ of them are women. With this result, the result can be tested and an improvement can be made in favor of women.

When the results are examined regardless of the name of the sector, it is seen that the color harmony of the participants, the sector in which the company is located and the target audience options come to the fore in the color preference of the participants.

Regardless of the industry, the colors representing excitement and energy in green logo designs are Red, loyalty, persistence, power, wisdom and reliability Black and blue, the symbol of usability, loyalty and relaxation, are the most preferred colors.

The other target is that there is a strong relationship between the color harmony of the participants, the sector of the company, customer demand, target audience characteristics and logo color preferences. In addition, it was observed that there was a strong relationship between the general color preferences of the participants and the colors they used in logo design.

As a result; Color preferences in design are influenced by factors such as the general trends of the designer and the sectors of the companies, target audience and customer requests. It has been determined that these factors, which are listed with the experience and experience of the designers, are effective in shaping the color preferences.

\section{Kaynakça / References}

Akkaya, M. (2008). Türkiye'de giyim eğitimi veren meslek liselerindeki öğrencilerin sanayi uygulamalarnnn işletmeler, öğrenciler ve koordinatör öğretmenler açısından değerlendirilmesi. Master tezi, Selçuk Üniversitesi Sosyal Bilimler Enstitüsü.

Akkaya, M., ve Kilınç, N. (2009). A survey on coordinator instructors involved in industrial practices of students in vocational training high schools offering clothing education in Turkey. Procedia-Social and Behavioral Sciences, 1(1), 2768-2775.

Arabi, A. (2017). Influence of colors on consumer behavior" conceptual and theoretical approaches". Annals of Constantin Brancusi'University of Targu-jiu. Economy Series, 3. 
Balcı, Ş, Kaya, E, Karadeniz, B, Abaylı, H . (2020). Aday imajı oluşumunda etkili faktörler: 31 Mart 2019 Yerel Seçimleri örneği. İletişim Kuram Ve Araştırma Dergisi, 50 ,1-27.https://Dergipark.Org.Tr/En/Pub/lkad/Issue/56157/738722

Bilirdönmez, K. (2020). Tipografide renk ve rengin kullanım1. Journal of Humanities and Tourism Research , 10 (4) , 863-883 . Retrieved from https://dergipark.org.tr/tr/pub/johut/issue/58659/847490

Bilirdönmez, T, Şahin, C . (2019). Doğu Karadeniz Bölgesi şehirlerinin belediye logolarundaki tanitic sembollerin analizi . Maarif Mektepleri Uluslararası Sosyal ve Beşeri Bilimler Dergisi , 2(2) , 38-47 . Retrieved from https://dergipark.org.tr/en/pub/mamusbbd/issue/51575/633102

Boz, Z., Korhonen, V., ve Koelsch Sand, C. (2020). Consumer considerations for the implementation of sustainable packaging: A review. Sustainability, 12(6), 2192.

Çalışkan, N, ve Kılıç, E. (2014). Farklı kültürlerde ve eğitimsel süreçte renklerin dili. Ahi Evran Üniversitesi Kurşehir Eğitim Fakültesi Dergisi , 15 (3) , 69-85 . https://Dergipark.Org.Tr/En/Pub/Kefad/Issue/59454/854164

Ceyhun Sezgin, A, ve Ayyldız, S. (2019). Çocukların tükettiği atışırmalık gıdalarda kullanılan renklendiricilere ilişkin bir araştırma. OPUS Uluslararası Toplum Araştırmalan Dergisi, 11 (18), 877-913. DOI: 10.26466/opus.552795470120

El-Abbadi, N. H., Taylor, S. F., Micha, R., ve Blumberg, J. B. (2020). Nutrient Profiling Systems, Front of Pack Labeling, and Consumer Behavior. Current atherosclerosis reports, 22(8), 1-10.

Girard, T., ve Hallman, L. (2017). Linking Education to Industry: A Collaborative Logo Design Project. Journal of Higher Education Theory and Practice, 17(6), 71-77.

Lipson, S. K, Kern, A., Eisenberg, D., ve Breland-Noble, A. M. (2018). Mental health disparities among college students of color. Journal of Adolescent Health, 63(3), 348356.

Machado, J. C., Fonseca, B., ve Martins, C. (2021). Brand logo and brand gender: examining the effects of natural logo designs and color on brand gender perceptions and affect. Journal of Brand Management, 28(2), 152-170.

Mazlum, Ö. (2011). Rengin Kültürel Çağrışımları. Dumlupınar Üniversitesi Sosyal Bilimler Dergisi ,31, Retrieved from https://dergipark.org.tr/en/pub/dpusbe/issue $/ 4773 / 65707$

Mert, Ö. (2019). Marmaray istasyonlarında yer alan bilgilendirme grafiklerinin incelenmesi. Maarif Mektepleri Uluslararası Sosyal ve Beşeri Bilimler Dergisi , 2(2) , 25-37. Retrieved from https://dergipark.org.tr/en/pub/mamusbbd/issue $/ 51575 / 621852$ 
Oduncu, S. (2020). Kitap kapağ tasarımlarında renk kullanımının cinsiyet odağnda değerlendirilmesi. Ulakbilge, 507-519. Doi: 10.7816/Ulakbilge-08-48-02

Özalp, H, ve Gökay, M. (2018). Farklı kültürler içerisinde eğitim gören 12-17 yaş grubu Türk Çocuklarının estetik beğeni düzeylerinin karşılaştırılması. OPUS Uluslararası Toplum Araştırmalan Dergisi, 9 (16), 1307-1368. DOI: 10.26466/opus.

Özomay, Z. (2020), Matbaa çalşsanlarının renk algilarının tespiti ile ilgili değerlendirme, Sosyal ve Beşerî Bilimlerde Teori ve Araştırmalar, Gece Kitaplı̆̆̆, 139-155.

Sağocak, M. D. (2005). Ergonomik tasarımda renk. Trakya Üniversitesi Fen Bilimleri Dergisi, 6(1), 77-83.

Şahin, C, Keskin, B, ve Köse, E. (2016). Meslek Yüksekokulları grafik tasarımı ders programlarında matbaa derslerinin yeri: İstanbul örneği . Ejovoc (Electronic Journal of Vocational Colleges), 6(1), 48-55. Retrieved from https://dergipark.org.tr/en/pub/ejovoc/issue/36628/416991

Tekvar, S. (2017). Pazarlama odaklı halkla ilişkilerde ürün paketleme ve sergileme stratejilerinin önemi. Kesit Akademi Dergisi, 7, 145-159. Retrieved From https://Dergipark.Org.Tr/En/Pub/Kesitakademi//ssue/59839/864722

Ustaoglu, F. D., ve Bayçu, S. U. (2015). Kurum kimliği: Logo ve rengin çağrişimlari. Selçuk Üniversitesi Sosyal Bilimler Enstitüsü Dergisi, (34), 27-40.

Uzuner, E. (2014). Renklerin ürün kimlï̆ine etkisi ve çözümleri. Doktora tezi, İstanbul Arel Üniversitesi.

\section{Kaynakça Bilgisi / Citation Information}

Özomay, Z., Keskin, B. and Şahin, C. (2021). Görsel iletişim tasarım bölümü öğrencilerinin sektörel logolardaki renk tercihleri. OPUS-International Journal of Society Researches, 17(37), 4181-4198. DOI: 10.26466/opus. 905191 